\begin{tabular}{|c|l|}
\hline Title & Expression and local ization of collagen type IV a 1 chain in medaka ovary \\
\hline Author(s) & Kato, Y umiko; Ogiwara, Katsueki; Fujimori, Chika; Kimura, A tsushi; Takahashi, Takay uki \\
\hline Citation & $\begin{array}{l}\text { Cell and Tissue Research, 340(3), 595-605 } \\
\text { https://doi.org/40.1007/300441-010-0969-5 }\end{array}$ \\
\hline Issue Date & 2010-06 \\
\hline Doc URL & http://hdl.handle.net/2115/49214 \\
\hline Rights & The final publication is available at www.springerlink.com \\
\hline Type & article (author version) \\
\hline File Information & CTR340-3_595-605.pdf \\
\hline
\end{tabular}

Instructions for use 


\title{
Expression and localization of collagen type IV $\alpha 1$ chain in the medaka ovary
}

\author{
Yumiko Kato · Katsueki Ogiwara • Chika Fujimori • Atsushi Kimura • \\ Takayuki Takahashi
}

Laboratory of Reproductive and Developmental Biology, Faculty of Advanced Life Science, Hokkaido University, Sapporo 060-0810, Japan

Corresponding author:

Takayuki Takahashi, Laboratory of Reproductive and Developmental Biology, Faculty of Advanced Life Science, Hokkaido University, Sapporo 060-0810, Japan

Phone: 81-11-706-2748 Fax: 81-11-706-4851 E-mail: ttakaha@sci.hokudai.ac.jp

Running title: Collagen type IV in the medaka ovary 


\begin{abstract}
A cDNA clone coding for collagen type IV $\alpha 1$ chain was obtained from the ovary of the medaka, Oryzias latipes. The clone encodes a protein of 1639 amino acids including a putative 21-residue signal peptide, and the deduced amino acid sequence of the $\alpha 1$ chain was homologous to those of the proteins from other species. Collagen type IV $\alpha 1$ chain mRNA was expressed in various tissues of the adult fish. In situ hybridization analysis revealed that the $\alpha 1$ chain mRNA was localized in the follicle layer of all growing follicles. In the post-ovulatory follicle that had released its oocyte in ovulation, the $\alpha 1$ chain transcript was detected in a winding line surrounding the tissue. This localization pattern was different from that of gelatinase B, a marker gene for granulosa cells. A specific antibody was prepared for the medaka collagen type IV $\alpha 1$ chain. Immunohistochemical analysis using this antibody yielded results consistent with those obtained by the in situ hybridization experiment. The current results indicate that in the medaka ovary, collagen type IV is synthesized by theca cells and is localized in the basement membrane.
\end{abstract}

Keywords medaka, ovary, collagen type IV $\alpha 1$, expression, distribution 


\section{Introduction}

Extracellular matrix (ECM) is an essential component of the stromal microenvironment. It was classically viewed as a supporting structure for stabilizing the location of cells in tissues and for preserving the architecture of tissues. However, this conception has changed dramatically over the past few decades. It is now well understood that ECM also has a profound influence on the structure, viability, and function of cells (Adair-Kirk and Senior 2008; Marastoni et al. 2008). ECM is a complex mixture of proteins, proteoglycans, and glycosaminoglycans. ECM proteins include collagens, laminins, and fibronectin. Collagens are a family of fibrous proteins found in all multicellular animals (Vuorio and Crombrugghe 1990). Based on their supramolecular structure, the collagens are divided into two main classes: fibril-forming (or fibrillar) collagens and non-fibril-forming collagens (Vuorio and Crombrugghe 1990; Khoshnoodi et al. 2008). Collagen type I is a fibril-forming collagen and by far the most abundant of the various collagen types in vertebrates. Another important group is collagen type IV, which is a non-fibril-forming collagen, and is the major constituent of basement membranes. Both collagen types I and IV are triple-helical proteins consisting of two or three kinds of fibrous $\alpha$ proteins. Major and typical molecular forms of collagen type I and collagen type IV are $\left[\alpha 1(\mathrm{I})_{2} \alpha 2(\mathrm{I})\right]$ and $\left[\alpha 1(\mathrm{IV})_{2} \alpha 2(\mathrm{IV})\right]$, respectively. Fibroblasts in the connective tissue are generally believed to be the cells that produce these ECM proteins (Vuorio and Crombrugghe 1990; Khoshnoodi et al. 2008).

A recent study of Aouacheria et al. (2006) revealed that type IV collagen shows a wide distribution in animals, from cnidarians to chordates. There have been numerous reports on 
type IV collagen in mammals, and a limited number of reports on this ECM protein in non-mammalian vertebrates or invertebrate species. The latter include studies showing the presence of collagen type IV in the basement membrane in Xenopus embryos (Bride et al. 1982), zebrafish embryos (Crawford and Pilgrim 2005) and adult tissues (MacDonald et al. 2009), Drosophila embryos (Medioni and Noselli 2005), and quail embryos (Song et al. 2000). However, little is known about the expression and distribution of collagen type IV in the ovaries of non-mammalian species, except for the recent report on the teleost Prochilodus argenteus ovary (Santos et al. 2008). That paper dealt with the relationship among follicular apoptosis, integrin $\beta 1$ and collagen type IV during early ovarian regression after spawning, and documented the localization of immunoreactive materials detectable with anti-human collagen type IV antibody in the fish ovary.

Ovulation, which is triggered by a surge of luteinizing hormone (LH) released from the pituitary, is an entire sequence of follicular responses leading to the release of fertilizable ova from the ovaries of animals. The climax of this process is the rupture of the follicle wall. Previous electron microscopic observation of the follicle wall demonstrated that collagen type I is abundantly present in the tunica albuginea and theca externa of fully grown follicles (Espey 1967). On the other hand, collagen type IV is present in the basal lamina separating granulosa and theca cells (Berkholtz et al. 2006; Lind et al. 2006). Therefore, follicle rupture should involve the degradation of collagen type I and type IV at the apex of ovulating follicles upon ovulation (Espey and Richards 2006). However, the mechanism of this degradation process remains largely undefined because a protease(s) responsible for follicle rupture has not yet been identified in mammals.

The medaka fish, Oryzias latipes, is a small egg-laying freshwater teleost that has 
advantages for use in various studies, including developmental, reproductive, and molecular genetic studies (Iwamatsu et al. 1988; Nagahama et al. 1994; Ozato and Wakamatsu 1994; Ishikawa et al. 2000; Wittbrodt et al. 2002; Kasahara et al. 2007). This lower vertebrate species is particularly attractive to researchers conducting ovarian function studies because of the manageable cyclicity of ovarian activity in the mature medaka fish. During the reproductive season, individual ovaries of the medaka contain oocytes in all phases of oogenesis. Oocytes can be grossly divided into five phases and further into ten stages, based on major morphological characteristics of developing oocytes and follicles (Iwamatsu et al. 1988). The fish also spawns daily within $1 \mathrm{~h}$ of the onset of light for a number of consecutive days when kept in the laboratory under a constant long photoperiod of $14 \mathrm{~h}$-light $/ 10 \mathrm{~h}$-dark at $26-28^{\circ} \mathrm{C}$. This enables us to determine the timing of a sequential process of spawning, such as completion of vitellogenesis, breakdown of the germinal vesicle and ovulation (Iwamatsu 1978). The endocrine background for the ovarian cyclicity has been previously elucidated (Nagahama 1994). Unlike fully grown mammalian follicles, the follicle layer of growing and fully grown follicles of the medaka consists of a single layer of granulosa cells surrounding an oocyte, a single layer of theca cells associated with a single layer of outermost ovary epithelial cells, and a basement membrane between the granulosa and theca cell layer (Pendergrass and Schroeder 1976; Iwamatsu and Ohta 1989). Only fully grown follicles with a large oocyte (about $1 \mathrm{~mm}$ in diameter) ovulate. Ovulation in the medaka is also presumed to be accompanied by the destruction of ECM proteins present in the follicle layer of ovulating follicles.

We have recently reported the involvement of three matrix metalloproteinases (MMPs), membrane type-1 MMP (MT1-MMP), MT2-MMP, and gelatinase A (or MMP-2), and an 
endogenous MMP inhibitor, the tissue inhibitor of metalloproteinase-2b (TIMP-2b), in the ovulation of the medaka (Ogiwara et al. 2005). To further understand the precise role of these MMPs in follicle rupture, information on the distribution of ECM proteins in ovulating follicles of the medaka is necessary. Our recent study showed that mRNA of the collagen type I $\alpha 1$ chain, $\alpha 1(\mathrm{I})$, is expressed in the theca cells of all growing ovarian follicles, suggesting the localization of collagen type I protein in the extracellular space of the theca cell layer (Horiguchi et al. 2008). In the present study, the expression and localization of collagen type IV $\alpha 1$ chain $(\alpha 1(\mathrm{IV}))$ in the medaka ovary were investigated. Our data indicate that, like $\alpha 1(\mathrm{I})$, the $\alpha 1$ (IV) protein is synthesized in and secreted from the theca cells of ovarian follicles.

\section{Materials and methods}

Animals and tissues

Experiments were conducted in our laboratory using mature medaka (Oryzias latipes) purchased from a local dealer. The fish were kept in indoor tanks under artificial reproductive conditions (photoperiod, 10-h dark/14-h light; temperature, $28^{\circ} \mathrm{C}$ ) (Iwamatsu, 1978). After becoming acclimated to the conditions, mature female fish ovulate in vivo each day at the start of the light period. The start of the light period was designated as ovulation hour 0. Ovaries and ovarian follicles were isolated for the experiments at various time points. The staging of ovarian follicles was carried out as described previously (Iwamatsu 1988): small (<0.5 mm in diameter, stages I-VI), medium $(0.5-1.0 \mathrm{~mm}$, stages VII-VIII), and large (>1.0 mm, stages IX-X) follicles. Follicle layers were obtained $2 \mathrm{~h}$ 
before ovulation as described previously (Ogiwara et al. 2005). Sexually immature ovaries were obtained from fish less than $15 \mathrm{~mm}$ in body length. Other tissues were obtained from the fish at $3 \mathrm{~h}$ after ovulation. The experimental procedures used in this study were approved by the Committee of the Center for Experimental Plants and Animals, Hokkaido University.

cDNA cloning of medaka $\alpha 1(\mathrm{IV})$

A partial nucleotide sequence for medaka $\alpha l(I V)$ was identified by a search program of the Ensembl genome browser (http://www.ensembl.org/index.html). The sequence (ID: ENSORLT00000022565, release 56), which was highly homologous to mammalian $\alpha 1(\mathrm{IV})$, was obtained by an initial reverse transcription-polymerase chain reaction (RT-PCR) using total RNA isolated from the follicle layers of ovulated follicles. The specific sense primer used 5' 5'-GGACAACCAGGGAAAAAAGGAGAACCTG-3' (1195-1222, ENSORLT0000002256), which corresponded to the nucleotide sequence 1322-1349 of our recently registered $\alpha I(I V)$ sequence (AB525196), and the antisense primer was 5'-TTGGGGCGTGAAATCAGTG-3' （5255-5273， ENSORLT00000022565), which corresponded to our $\alpha 1(I V)$ nucleotide sequence 5343-5361 (AB525196). PCR was conducted using KOD fx DNA polymerase (Toyobo, Osaka, Japan), and the PCR conditions were $94^{\circ} \mathrm{C}$ for $2 \mathrm{~min}$; followed by 40 cycles of $10 \mathrm{sec}$ at $94^{\circ} \mathrm{C}$ and $10 \mathrm{~min}$ at $68^{\circ} \mathrm{C}$. The amplified product was gel-purified, cloned into the pBluescript II plasmid vector (Stratagene, La Jolla, CA), and sequenced. 
The nucleotide sequences of the upstream and downstream regions were obtained by the 5'-RACE method (Frohman et al. 1988) and 3'-RACE method (Frohman et al. 1988), respectively. Using the same total RNA, the 5'-RACE method was performed twice using a 5'-RACE system, Version 2 (Invitrogen, Carlsbad, CA), according to the manufacturer's protocol. For the first RACE, the antisense primers used were 5'-GTCTCCTTTGCTGCCAACTG-3' (1548-1567, AB525196), 5'-CCAATTATACCACTGGTCTC-3' (1481-1500, AB525196), and 5'-GAACACACGTGTCTCCTTTAT-3' (1455-1475, AB525196). For the second RACE, the antisense primers used were 5'-TTGACCGTCCTCGCCATCTT-3' (1023-1042, AB525196), 5'-TCACCTTTAATCCCATGCTG-3' (968-987, AB525196), and 5'-AAGCCTTTTTCTCCTCTGTC-3' (935-954, AB525196). The 3'-RACE method was conducted using a 3'-Full RACE Core Set (TaKaRa, Tokyo, Japan) according to the manufacturer's protocol. The sense primers used were 5'-AGCCCTTTAAACAACAAGA-3' (5129-5147, AB525196) and 5'-ACCGGTGTTCTGGCTTTAC-3' (5153-5171, AB525196). Amplified products were gel-purified and sequenced. The sequences obtained by the 5'- and 3'-RACE methods were confirmed by RT-PCR using KOD fx DNA polymerase.

Primary cell culture of medaka ovarian granulosa cells

Ovaries were obtained from mature female medaka at $3 \mathrm{~h}$ before ovulation, and large-sized follicles that were about to ovulate were isolated. The follicle layers, which consist of granulosa cells and theca cells, were mechanically separated from the oocytes by 
using forceps, and were washed three times with phosphate buffered saline (PBS). After washing, the tissues were placed in PBS containing $0.25 \%$ trypsin and $1 \mathrm{mM}$ EDTA and gently rotated for $30 \mathrm{~min}$ at room temperature. The treated samples were collected by centrifuging at 2,000 rpm for 3 min. After washing three times with $90 \%$ medium 199 solution (Earle's medium 199; Dainippon Seiyaku, Osaka, Japan) adjusted to pH 7.4 with $\mathrm{NaHCO}_{3}$, the precipitated materials containing various types of ovarian cells were filtrated with a $100 \mu \mathrm{m}$ Nylon BD Falcon ${ }^{\mathrm{TM}}$ Cell strainer (BD Biosciences, Bedford, MA), and cultured at $26^{\circ} \mathrm{C}$ in a 24 -well gelatin coating tissue-culture plate using the same medium containing $50 \mu \mathrm{g} / \mathrm{ml}$ gentamycin and $5 \%$ carp serum. After $48 \mathrm{~h}$ of culture, the plate was gently washed with PBS to remove un-attached cells and the cells remaining attached to the dish were collected. The viability of the cells thus obtained was estimated to be more than $95 \%$. The vast majority of these cells were judged to be granulosa cells based on expression profiles of several marker genes.

Semi-quantitative RT-PCR analysis

Total RNA samples were isolated from various tissues, ovarian follicles, and cultured follicular cells using Isogen (Nippon Gene, Tokyo, Japan) according to the manufacturer's instructions, and the amount and purity were determined by spectrophotometry. Semiquantitative RT-PCR analysis was conducted as described previously (Ogiwara et al. 2005). PCR was conducted using Ex taq DNA polymerase (TaKaRa), and the PCR conditions were $94^{\circ} \mathrm{C}$ for $3 \mathrm{~min}$; followed by 25 cycles of $30 \mathrm{sec}$ at $94^{\circ} \mathrm{C}, 30 \mathrm{sec}$ at $60^{\circ} \mathrm{C}$, and $30 \mathrm{sec}$ at $72^{\circ} \mathrm{C}$. The medaka cytoplasmic actin (Olca-1) gene was used as an internal 
control (Kusakabe et al. 1999). The primers used are shown in Table 1. The signal intensities of the products were quantified by densitometric analysis, and the data from PCR were normalized with the control genes. The ratio of the $\alpha l(I V)$ mRNA to the control was determined from three separate experiments.

In situ hybridization

RNA probes were prepared by in vitro transcription of reverse transcriptase fragments of $\alpha l(I V)$ (corresponding to the 3'-noncoding sequence of 5153-5361) with T3 or T7 RNA polymerase using a digoxigenin (DIG) RNA labeling mix (Roche Diagnostics, Basel, Switzerland). Ovary sections $(12 \mu \mathrm{m})$ of medaka fish were cut on a cryostat and thaw-mounted onto slides coated with silane. Sections on slides were fixed in $4 \%$ paraformaldehyde (Wako Pure Chemicals, Osaka, Japan) in PBS for $15 \mathrm{~min}$ at room temperature and washed with PBS three times. The sections were acetylated for $10 \mathrm{~min}$ with $0.25 \%$ acetic anhydride in $0.1 \mathrm{M}$ of triethanolamine/ $\mathrm{HCl}$ buffer $(\mathrm{pH} 8.0)$. The hybridization was conducted at $60^{\circ} \mathrm{C}$ for $18 \mathrm{~h}$ in $50 \%$ formamide, $0.5 \mathrm{M} \mathrm{NaCl}, 10 \mathrm{mM}$ Tris- $\mathrm{HCl}(\mathrm{pH} 8.0), 10 \%$ dextran sulfate, $1 \times$ Denhardt's solution, $0.25 \%$ sodium dodecyl sulfate, and $0.2 \mathrm{mg} / \mathrm{ml}$ yeast transfer RNA. The sections were consecutively washed at $60^{\circ} \mathrm{C}$ in $50 \%$ formamide $/ 2 \times \mathrm{SSC}$ for $30 \mathrm{~min}$, at $60^{\circ} \mathrm{C}$ in $2 \times \mathrm{SSC}$ for $20 \mathrm{~min}$, and then at $60^{\circ} \mathrm{C}$ in $0.2 \times \mathrm{SSC}$ for $20 \mathrm{~min}$. The hybridization probes were detected using a Dig Nucleic Acid Detection Kit (Roche).

In situ hybridization for gelatinase B was performed as previously described (Matsui et al. 2000), except that hybridization and washing were conducted at $60^{\circ} \mathrm{C}$. 
Preparation of antibodies for medaka $\alpha 1(\mathrm{IV})$ protein

A cDNA fragment (2831-3595, AB525196) encoding part of the triple-helical domain of the $\alpha 1(\mathrm{IV})$ chain (residue 891 to residue 1145; total 255 residues) was generated by RT-PCR and ligated in-frame to the NdeI and HindIII sites of the vector pET30a (Novagen,

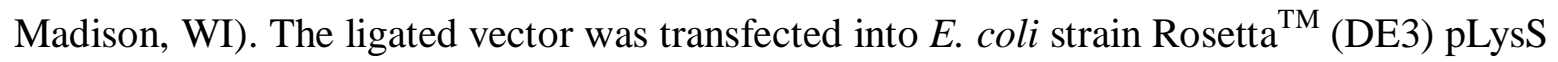
cells (Novagen). Lysis of harvested cells, affinity-chromatography on $\mathrm{Ni}^{2+}$-Sepharose (GE Healthcare Biosciences, Piscataway, NJ), and refolding of the eluted recombinant protein were conducted as described previously (Ogiwara et al. 2005). The protein thus prepared was used for an antigen. Five mice were immunized with the recombinant protein.

Preparation of medaka collagen type IV

The whole bodies of several medaka fish were used for acetic acid extraction of the collagen (Ogiwara et al. 2005). The fraction, which contained the type I collagen (>90\%) and some other types of collagens, including the type IV collagen, was further subjected to salting-out with $0.2 \mathrm{M} \mathrm{NaCl}$. By repeating the $\mathrm{NaCl}$ precipitation five times, the enrichment of collagen type IV was achieved.

Western blot analysis

Western blot analysis was performed as described previously (Ogiwara et al. 2007), except that signals were detected using an Immunobilon ${ }^{\mathrm{TM}}$ Western kit (Millipore, Bedford, MA) according to the protocol provided by the manufacturer. Protein concentrations were 
determined using a BCA Protein Assay Reagent Kit (Thermo, Rockford, IL).

Immunohistochemistry

Ovary sections $(12 \mu \mathrm{m})$ were cut on a cryostat and thaw-mounted onto slides coated with 3-aminopropyl triethoxysilane. Sections on slides that were fixed with $4 \%$ paraformaldehyde in PBS for 15 min were treated with $3 \% \mathrm{H}_{2} \mathrm{O}_{2}$ in PBS. After being blocked with BlockAce (Dainippon-Sumitomo Seiyaku, Osaka, Japan) for $1 \mathrm{~h}$ at room temperature, sections were incubated with primary antibody for $1 \mathrm{~h}$ at room temperature. They were then washed with PBS and incubated with the secondary antibody, anti-mouse IgG horseradish peroxidase-linked whole antibody (GE Healthcare Biosciences), for $1 \mathrm{~h}$ at room temperature. After washing with PBS, immunocomplexes were detected using an AEC kit (Vector Laboratories, Burlingame, CA).

Immunohistochemistry for gelatinase B was performed as described previously (Ogiwara et al. 2005).

Statistical analysis

Data are presented as the mean \pm SEM of three independent experiments. Differences between groups were evaluated by Student's $t$-test.

\section{Results}

cDNA cloning of the medaka $\alpha 1$ (IV)

A cDNA clone (6371 bp) coding for the medaka $\alpha 1(\mathrm{IV})$ protein was obtained. The 
clone consisted of a 160-bp 5'-untranslated region, a 4920-bp open reading frame, and a 1291-bp 3'-untranslated region (DDBJ/EMBL/GenBank, Accession no. AB525196) (Fig. 1). A protein of 1639 amino acids, including a putative signal peptide of 21 residues, was encoded by the clone. The mature $\alpha 1$ protein contained three structurally distinct domains: an amino-terminal 7S domain ( Lys $^{22}-\mathrm{Gly}^{164}$ ), followed in order by a major collagenous Gly-Xaa-Yaa triple repeats $\left(\right.$ Lys $^{166}-$ Ser $^{1410}$ ) domain, and a long carboxyl-terminal noncollagenous ( $\mathrm{NC1})$ domain $\left(\mathrm{Ser}^{1411}-\mathrm{Thr}^{1639}\right)$. In the $7 \mathrm{~S}$ domain, the locations of all five cysteine residues and eight lysine residues, which are essential for interchain crosslinking of four triple-helical molecules through disulfide bonds and lysine-hydroxylysine crosslinks (Rowe and Weiss 2008; Khoshnoodi et al. 2008), were conserved (Fig. 2). The collagenous Gly-Xaa-Yaa triple repeats were interrupted at 22 sites in the sequence ranging from the $7 \mathrm{~S}$ domain to the triple-helical domain. An Arg-Gly-Asp (RGD) motif, which could represent a potential cell-binding site, was present at four positions $(584-586,875-877,1117-1119$, and 1135-1137) in the collagenous Gly-Xaa-Yaa triple helical domain. In the NC1 domain of the medaka $\alpha 1$ (IV), twelve cysteine residues were all conserved (Fig. 3).

The primary structure of the medaka $\alpha 1$ (IV) was compared with those of other species (Table 2). The greatest similarity of amino acid sequence was found in the carboxyl-terminal $\mathrm{NC1}$ domain, which showed $86 \%$ identity with its counterparts in mammalian species.

Expression of $\alpha l(I V)$ mRNA in the medaka ovary

RT-PCR analysis of $\alpha l(I V)$ mRNA was conducted for various tissues of the adult fish 
(Fig. 4a). The expression of $\alpha l(I V)$ mRNA was observed in all tissues examined, although the level of the transcript was low in the liver and ovary. The expression of $\alpha l(I V)$ mRNA was significantly higher in the mature medaka ovary than the immature fish ovary (Fig. 4b). The level of the $\alpha l(I V)$ transcript tended to increase as the ovarian follicles grew (Fig. 4c).

In situ detection of $\alpha l(I V)$ mRNA was performed using sections of mature fish ovaries isolated at $1 \mathrm{~h}$ after ovulation. Follicle layers of all growing follicles except primary follicles at stage I and II were stained with the antisense probe; signals associated with large- and medium-sized follicles were intense while those associated with small-sized follicles were weak (Fig. 5a, arrow). A clear signal was observed in the follicle tissue that had ovulated and migrated into the central area of the ovary (Fig. 5a, arrowhead). In that area, the staining resembled a series of winding lines, which corresponded to the theca cell layer of the ovulated follicle. For comparison, the neighboring sections were stained in parallel for the transcript of gelatinase $B$, a known marker for granulosa cells of post-ovulatory follicles. In the post-ovulatory follicles, gelatinase $B$ signals were present in the interior, but not the exterior, of the tissue (Fig. 5b). No signals were observed when the sense probes were used (Fig. 5, $\mathrm{c}$ and d).

To gain further information on cells expressing $\alpha l(I V)$ mRNA in the fish ovary, RT-PCR analysis was conducted with total RNAs separately isolated from follicle layers, which contained granulosa cells and theca cells, and the granulosa cells of large-sized follicles (Fig. 6). The oocyte-free follicle layer contained gelatinase $B$ (a marker for granulosa cells) (Ogiwara et al. 2005) and $\alpha 1(I)$ mRNA (a marker for theca cells) (Horiguchi et al. 2008), but not MT3-MMP (markers for oocytes) (Ogiwara et al. 2005) (Fig. 
6, left panel). On the other hand, only gelatinase B mRNA and the control Olca-1 mRNA were detected in the isolated granulosa cells (Fig. 6, right panel), indicating a lack of $\alpha l(I V)$ mRNA expression in the granulosa cells. When the number of PCR cycles was increased, the PCR products for $\alpha l(I)$ and $\alpha l(I V)$ were detectable (data not shown). This finding may indicate that the granulosa cells also express both $\alpha l(I)$ and $\alpha l(I V)$, though the levels of the transcripts are very low. Alternatively, our granulosa cell fraction might have been slightly contaminated with theca cells.

Collectively, the above results strongly suggest that the cells expressing $\alpha I(I V)$ mRNA in the ovarian follicle are theca cells, but not granulosa cells.

Localization of $\alpha 1(\mathrm{IV})$ protein in the medaka ovary

An antibody was raised for the medaka $\alpha 1(\mathrm{IV})$ protein, and the specificity of the antibody was assessed by Western blotting. The antibody recognized the 32-kDa recombinant antigen protein (Fig. 7a). It also detected the 140-kDa polypeptide when the acetic acid-extracted, $\mathrm{NaCl}$-precipitated collagen fraction was used (Fig. 7b). These results indicate that the antibody was specific for the medaka $\alpha 1(\mathrm{IV})$ protein.

The distribution of $\alpha 1(\mathrm{IV})$ protein on the ovary sections was examined using the specific antibody. Positive signals were detected in association with the follicle layer of all follicles except the primary follicles at stages I and II (Fig. 8, a and c). The follicular tissue, which had ovulated and subsequently moved into the interior interstitial areas of the ovary, also showed a clear signal (Fig. 8d). When compared with the localization of gelatinase B protein, the signals were restricted to a more exterior area of the tissue (Fig. 8e). The results 
of the medaka $\alpha 1(\mathrm{IV})$ protein distribution in the ovary were consistent with those of the in situ hybridization analysis shown in Fig. 5.

\section{Discussion}

Medaka $\alpha 1(\mathrm{IV})$ cDNA coded a protein of 1639 amino acids that included a putative signal peptide. The length of the protein is 24 amino acids shorter than the 1663 residue sequence (ID: ENSORLT00000022565) in Ensembl, release 56. It should be noted that the Ensembl sequence is the one simply deduced from genomic data and that its translation start site (Met) is not determined. When our sequence was compared with the Ensembl sequence, the following differences were apparent. The current sequence contains a 7-residue insertion and deletions at five sites. In addition, there are single-residue substitutions at three sites. The 1639-residue number of the medaka $\alpha 1$ protein is comparable to the sizes of known collagen type IV $\alpha 1$ proteins: 1669 residues in humans (Brazel et al. 1987) and 1775 residues in Drosophila (Blumberg et al. 1988). The striking homology of the amino acid sequence to those of $\alpha 1$ (IV) from other species, together with the presence of characteristic domain structures (an $\mathrm{NH}_{2}$-terminal $7 \mathrm{~S}$ domain, a central discontinuous triple-helical domain rich in Gly-X-Y motifs, and a COOH-terminal NC1

domain), strongly suggests that the $\alpha 1$ protein serves as a constituent polypeptide of the medaka collagen type IV molecule. Like its mammalian counterparts (Vuorio and Crombrugghe 1990), the 7S domain of the medaka $\alpha 1$ protein consists of a Cys-rich noncollagenous segment, through which four collagen type IV molecules interact. The NC1 domain at the $\mathrm{COOH}$-terminus also contains all $\mathrm{Cys}$ residues that are presumed to be 
involved in the interaction of the two collagen molecules end-to-end. Therefore, at least for the $\alpha 1$ protein, the structural requirements for the formation of a flexible three-dimensional network to construct basement membranes are met.

In situ hybridization analysis of $\alpha 1(\mathrm{IV})$ mRNA as well as immunohistochemical analysis of the protein both localized signals to the follicle layer of all growing follicles. Ovarian follicles of the medaka are composed of two major cell layers, an outer theca cell layer and an inner granulosa cell layer, that are separated by a distinct basement membrane (Nagahama 1983). Since little or no PCR product was amplified by RT-PCR for $\alpha 1$ (IV) with total RNA prepared from primary cultured ovarian granulosa cells of the fish, and since its morphological staining pattern in the ovary was different from that of gelatinase B, which is a marker for granulosa cells (Matsui et al. 2000; Ogiwara et al. 2005), it is reasonable to conclude that the $\alpha 1$ (IV) gene is expressed in the theca cells of ovarian follicles in the medaka ovary. Similarly, signals detected by immunohistochemical analysis using our specific antibodies were found in the follicle layer. We therefore presume that $\alpha 1(I V)$ is synthesized in and secreted from the theca cells of the follicle to constitute the basement membrane of the follicle layer. Our results are consistent with the recent observations of Santos et al. (2008) on the ovary of the curimata-pacu, Prochilodus argenteus. In several mammalian species, collagen IV has also been reported to be immunolocalized to the theca cell compartment for all follicle stages of ovarian follicles (Bortolussi et al. 1989; Frojdman et al. 1998; Zhao and Luck 1995; Rodgers et al. 1998; Irving-Rodgers et al. 2002; Iwahashi et al. 2000; Berkholtz et al. 2006). These facts tempt us to speculate that theca cells serve to supply collagen type IV to form and/or maintain the 
basement membrane in the follicle layer of ovarian follicles in all vertebrate species.

The current study, together with our previous study (Horiguchi et al. 2008), demonstrates that theca cells of medaka ovary growing follicles express both collagens type I and type IV. The expression patterns of their respective transcripts in the follicle are temporally and spatially very similar. Whether or not a common regulatory mechanism may operate for these two different genes in the cells is unknown at present. In mammals, the collagen type I gene is generally believed to be expressed in fibroblasts, which were electron microscopically proved to be present in the fibrous connective tissue (the tunica albuginea and theca externa) of the follicle (Espey 1999). In contrast, no fibroblasts are observed in the follicle cell layer of the medaka (Pendergrass and Schroeder 1976; Schroeder and Pendergrass 1976; Iwamatsu and Ohta 1989). Due to the characteristic structure of the follicle cell layer, which consists of only two types of cells (granulosa and theca cells), the theca cells may have come to possess a dual role, functioning not only as endocrine cells producing steroid hormones but also as fibroblast-like cells producing the ECM proteins collagen type I and type IV.

In summary, this study reports for the first time the distribution of collagen type IV in the ovary of the lower vertebrate medaka. The results support our hypothesis that the collagen type IV present in the basement membrane of the follicle is degraded upon ovulation.

\section{Acknowledgments}

This study was supported in part by Grants-in-Aid for Scientific Research from the Ministry of Education, Science, Sports, and Culture of Japan. 


\section{References}

Adair-Kirk TL, Senior RM (2008) Fragments of extracellular matrix as mediators of inflammation. Int J Biochem Cell Biol 40: 1101-1110

Aouacheria A, Geourjon C, Aghajari N, Navratil V, Deleage G, Lethias C, Exposito J-Y (2006) Insights into early extracellular matrix evolution: Spongin short chain collagen-related proteins are homologous to basement membrane type IV collagens and from a novel family widely distributed in invertebrates. Mol Biol Evol 23: 2288-2302

Berkholtz CB, Shea LD, Woodruff TK (2006) Distribution of extracellular matrix proteins collagen type I, type IV collagen, fibronectin, and laminin in mouse folliculogenesis. Histochem Cell Biol 126: 583-592

BlumbergB, Kackrell AJ, Fessler JH (1988) Drosophila basement membrane procollagen $\alpha 1($ IV). II. Complete cDNA sequence, genomic structure, and general implications for supramolecular assemblies. J Biol Chem 263: 18328-18337

Bortolussi M, Zanchetta R, Doliana R, Castellani I, Bressan GM, Lauria A (1989) Changes in the organization of the extracellular matrix in ovarian follicles during the preovulatory phase and atresia. An immunofluorescence study. Basic Appl Histochem 33: $31-38$

Brazel D, Oberbaumer I, Dieringer H, Babel W, Glanville RW, Deutzmann R, Kuhn K (1987) Completion of the amino acid sequence of the $\alpha 1$ chain of human basement membrane collagen (type IV) reveals 21 non-triplet interruptions located within the collagenous domain. Eur J Biochem 168: 529-536 
Bride M, Bensllimane S, Stocker S, Grimaud JA (1982) Detection of collagen by immunofluorescence during development of Xenopus (Xenopus laevis Daud.). C R Seances Soc Biol Fil 174: 494-502

Crawford BD, Pilgrim DB (2005) Ontogeny and regulation of matrix metalloproteinase activity in the zebrafish embryo by in vitro and in vivo zymography. Dev Biol 286: $405-414$

Espey LL (1967) Ultrastructure of the apex of the rabbit graafian follicle during the ovulatory process. Endocrinology 81: 267-276

Espey LL (1999) Ovulation. In: Knobil E, Neill JD (eds) Encyclopedia of Reproduction, vol. 3. Academic Press, San Diego, pp 605-614

Espey LL, Richards JS (2006) Ovulation. In: Neill JD et al. (eds) Knobil and Neill's Physiology of Reproduction, vol. 1. 3rd edition. Academic Press, Amsterdam, pp $425-474$

Frohman MA, Dush MK, Martin GR (1988) Rapid production of full-length cDNAs from rare transcripts: amplification using a single gene-specific oligonucleotide primer. Proc Natl Acad Sci USA 85: 8998-9002

Frojdman K, Pellinieme LJ, Virtanen I (1998) Differential distribution of the type IV collagen chains in the developing rat testis and ovary. Differentiation 63: 125-130

Horiguchi M, Fujimori C, Ogiwara K, Moriyama A, Takahashi T (2008) Collagen type-I $\alpha 1$ chain mRNA is expressed in the follicle cells of the medaka ovary. Zool Sci 25 : 937-945

Irving-Rodgers HF, Mussard ML, Kinder JE, Rodgers RJ (2002) Composition and 
morphology of the follicular basal lamina during atresia of bovine antral follicles. Reproduction 123: 97-106

Ishikawa Y (2000) Medakafish as a model system for vertebrate developmental genetics. BioEsseys 22: 487-495

Iwahashi M, Muragaki Y, Ooshima A, Nakano R (2000) Type IV collagen expression during growth of human ovarian follicles. Fertil Steril 74: 343-347

Iwamatsu T (1978) Studies on oocyte maturation of the medaka, Oryzias latipes. VI. Relationship between the circadian cycle of oocyte maturation and activity of the pituitary gland. J Exp Zool 206: 355-364

Iwamatsu T, Ohta T (1989) Effects of forskolin on fine structure of medaka follicles. Develop Growth Differ 31: 45-53

Iwamatsu T, Ohta T, Oshima E, Sakai N (1988) Oogenesis in the medaka Oryzias latipes. Stages of oocyte development. Zool Sci 5: 353-373

Kasahara M, Naruse K, Sasaki S et al. (2007) The medaka draft genome and insights into vertebrate genome evolution. Nature 447: 714-719

Khoshnoodi J, Pedchenko V, Hudson BG (2008) Mammalian collagen IV. Microscopy Res Tech 71: 357-370

Kusakabe R, Kusakabe T, Suzuki N (1999) In vivo analysis of two striated muscle actin promoters reveals combinations of multiple regulatory modules required for skeletal and cardiac muscle-specific gene expression. Int J Dev Biol 43:541-554

Lind AK, Weijdegard B, Dahm-Kahler P, Molne J, Sundfeldt K, Brannstrom M (2006) Collagens in the human ovary and their changes in the perifollicular stroma during ovulation. Acta Obstet Gynecol 85: 1476-1484 
MacDonald BA, Sund M, Grant MA, Pfaff KL, Holthaus K, Zon LI, Kalluri R (2009) Zebrafish to humans: evolution of the $\alpha 3$-chain of type IV collagen and emergence of the autoimmune epitopes associated with Goodpasture syndrome. Blood 107: 1908-1915

Marastoni S, Ligresti G, Lorenzon E, Colombatti A, Mongiat M (2008) Extracellular matrix: A matter of life and death. Connect Tissue Res 48: 203-206

Matsui H, Ogiwara K, Ohkura R, Yamashita M, Takahashi T (2000) Expression of gelatinases A and B in the ovary of the medaka fish, Oryzias latipes. Eur J Biochem 267: $4658-4667$

Medioni C, Noselli S (2005) Dynamics of the basement membrane in invasive epithelial clusters in Drosophila. Development 132: 3069-3077

Nagahama Y (1983) The functional morphology of teleost gonads. In: Hoar WS, Randall DJ, Donaldson EM (eds) Fish Physiology, vol IXA. Academic Press, New York, pp $223-275$

Nagahama Y (1994) Endocrine regulation of gametogenesis in fish. Int J Dev Bio 38: $217-229$

Nagahama Y, Yoshikuni M, Yamashita M, Tanaka M (1994) Regulation of oocyte maturation in fish. In: Sherwood NM, Hew CL (eds) Fish Physiology, Academic Press, New York, pp 393-439

Ogiwara K, Takahashi T (2007) Specificity of the medaka enteropeptidase serine protease and its usefulness as a biotechnological tool for fusion-protein cleavage. Proc Natl Acad Sci USA 104:7021-7026. 
Ogiwara K, Takano N, Shinohara M, Murakami M, Takahashi T (2005) Gelatinase A and membrane-type matrix metalloproteinases 1 and 2 are responsible for follicle rupture during ovulation in the medaka. Proc Natl Acad Sci USA 102: 8442-8447

Ozato K, Wakamatsu Y (1994) Developmental genetics of medaka. Dev Growth Differ 36: $437-443$

Pendergrass PC, Schroeder P (1976) The ultrastructure of the thecal cell of the teleost, Oryzias latipes, during ovulation in vitro. J Reprod Fertil 47: 229-233

Rodgers HF, Irvine CM, van Wezel IL, Lavranos TC, Luck MR, Sado Y, Ninomiya Y, Rodgers RJ (1998) Distribution of the alpha1 to alpha6 chains of type IV collagen in bovine follicles. Biol Reprod 59: 1334-1341

Rowe RG, Weiss SJ (2008) Breaching the basement membrane: who, when and how? Trends Cell Biol 18: 560-574

Santos HB, Sato Y, Moro L, Bazzoli N, Rizzo E (2008) Relationship among follicular apoptosis, integrin $\beta 1$ and collagen type IV during early ovarian regression in the teleost Prochilodus argenteus after induced spawning. Cell Tissue Res 332: 159-170

Schroeder P, Pendergrass PC (1976) The inhibition of in-vitro ovulation from follicles of the teleost, Oryzias latipes, by cytochalasin B. J Reprod Fertil 48: 327-330

Song W, Jackson K, McGuire PG (2000) Degradation of type IV collagen by matrix metalloproteinases is an important step in the epithelial-mesenchymal transformation of the endocardial cushions. Dev Biol 227: 606-617

Vuorio E, de Crombrugghe B (1990) The family of collagen genes. Annu Rev Biochem 59: $837-872$ 
Wittbrodt J, Shima A, Schartl M (2002) Medaka--a model organism from the far EastNat Rev Genet 3: 53-64

Zhao Y, Luck MR (1995) Gene expression and protein distribution of collagen, fibronectin and laminin in bovine follicles and corpora lutea. J Reprod Fertil 104: 115-123 


\section{FIGURE LEGENDS}

Fig. 1 Schematic representation of the medaka collagen $\alpha 1$ (IV) domain structure

The upper bold line represents the collagen type IV $\alpha 1$ chain cDNA. Figures above the line indicate the start site nucleotide number of the cDNA for four distinct domains. The line below the bold line indicates the position of a probe for in situ hybridization analysis. The domain structure of the $\alpha 1$ chain protein is shown below with the numbers of amino acids constituting each domain. The broken line indicates the portion selected for the recombinant protein production. SP, signal peptide; 7S, 7S domain; $\mathrm{NC1}$, noncollagenous domain.

Fig. 2 Comparison of the amino acid sequence of the collagen $\alpha 1$ (IV) $7 \mathrm{~S}$ domain with those of other species

The alignment for the amino acid sequence of the collagen type IV $\alpha 1$ chain $7 \mathrm{~S}$ domain is shown. The sequence of the $7 \mathrm{~S}$ domain of medaka was compared with those of humans (NP_001836), mice (NP_034061), and zebrafish (NP_001116702). The five conserved cysteine residues (asterisks) and eight lysine residues (filled squares) are indicated.

\section{Fig. 3 Alignment of the amino acid sequence of the collagen $\alpha 1$ (IV) NC1 domain}

The sequence of the NC1 domain of medaka collagen type IV $\alpha 1$ chain was compared with those of humans (NP_001836), mice (NP_034061), and zebrafish (NP_001116702). The twelve conserved cysteine residues are marked with asterisks. 


\section{Fig. 4 Expression of $\alpha l(I V)$ mRNA}

(a) The tissue distribution was analyzed by RT-PCR using total RNA isolated from various tissues. The lower panel shows the expression of Olca-1 as an internal control. (b) Comparison of the $\alpha l(I V)$ mRNA levels in the ovaries of immature and mature medaka was made by RT-PCR. The expression levels were normalized to that of Olca-1 and are shown in the lowest panel. (c) Changes in $\alpha I(I V)$ mRNA during follicle growth were investigated by RT-PCR. The expression levels were normalized to that of Olca-1 and are shown in the lowest panel. In all experiments, values represent the mean \pm SEM of three independent experiments. The asterisk indicates a significant difference $(\mathrm{P}<0.05)$.

\section{Fig. 5 Localization of $\alpha l(I V)$ mRNA in the ovary}

In situ hybridization analysis was performed on the sections of ovary at $1 \mathrm{~h}$ after ovulation using a digoxigenin-labeled $\alpha 1(\mathrm{IV})$ antisense probe (a) or sense probe (c). For identification of the cells expressing $\alpha l(I V)$ mRNA, the neighboring section was hybridized with a digoxigenin-labeled gelatinase $B$ antisense probe (b) or sense probe (d). Note that $\alpha l(I V)$ mRNA was localized in the follicle layer (arrows) of follicles and the external area of the follicle layer that had released an oocyte (arrowhead). Also note that gelatinase $B$ mRNA is only detected in the internal area, but not the external area, of the follicle layer that had released an oocyte. Bars represent $200 \mu \mathrm{m}$.

\section{Fig. 6 Gene expression analysis of medaka ovarian follicle layers and granulosa cells}

RT-PCR analysis for $\alpha l(I V)$ was carried out. For comparison, the expressions of 
MT3-MMP (markers for oocytes), $\alpha 1(I)$ (a marker for theca cells), gelatinase $B$ (a marker for granulosa cells), and Olca-1 (as a control) were also examined. The sequences of the RT-PCR primers used are shown in Table 1.

\section{Fig. 7 Specificity of anti- $\alpha 1($ IV) antibody}

The purified recombinant protein (a) or acid-soluble fraction purified with $\mathrm{NaCl}$ precipitation (b) was subjected to SDS-PAGE and stained with Coomassie Brilliant Blue (left panel) or analyzed by Western blotting using anti- $\alpha 1$ (IV) antibody (right panel).

\section{Fig. 8 Localization of $\alpha 1(\mathrm{IV})$ protein in the ovary}

Immunohistochemical analysis was performed on the sections of the fish ovary isolated at 1 $\mathrm{h}$ after ovulation. The sections were reacted with anti- $\alpha$ (IV) antiserum (a) or normal serum (b). A high magnification of panel a is shown in panels $\mathrm{c}$ and d. For comparison, immunohistochemical analysis for gelatinase B was also performed on the neighboring section (e). Note that the $\alpha 1(\mathrm{IV})$ protein is localized in the follicle layer of growing follicles (arrows) as well as the external area of the follicle layer in the postovulatory follicular tissue (arrowhead). No clear signal was observed in primary follicles at stages I and II (asterisk). Also note that the gelatinase B protein was only detected in the internal area, but not the external area, of the follicle layer in the postovulatory follicular tissue (white arrowhead). Scale bars: panels a and b represent $500 \mu \mathrm{m}$; panels c, d, and e represent 100 $\mu \mathrm{m}$. 


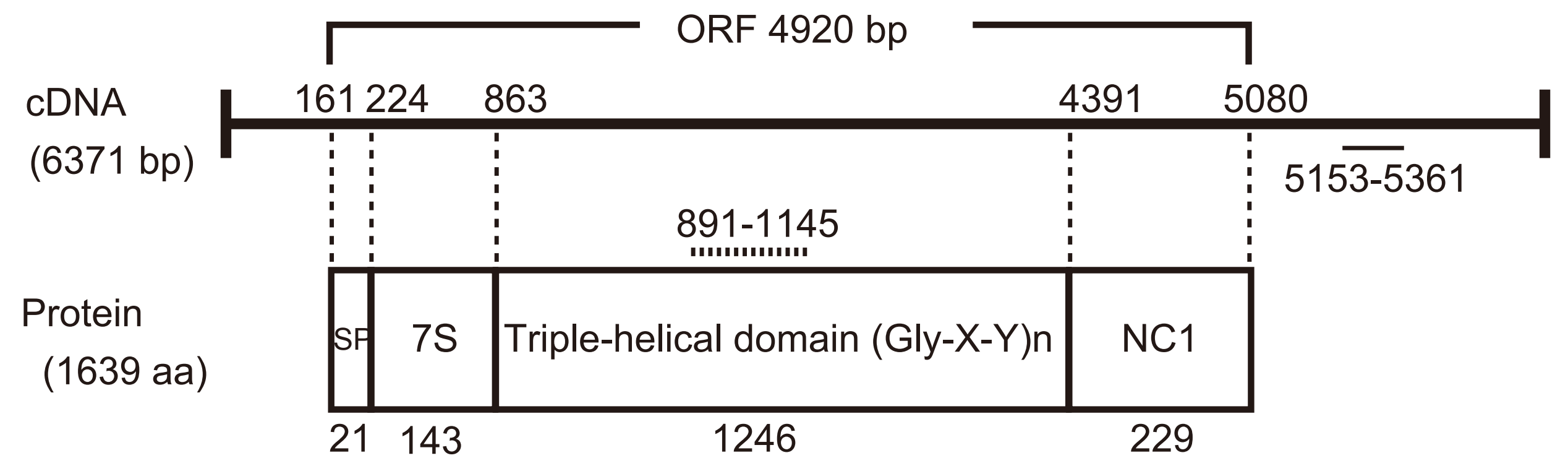

Fig. 1 Kato et al 


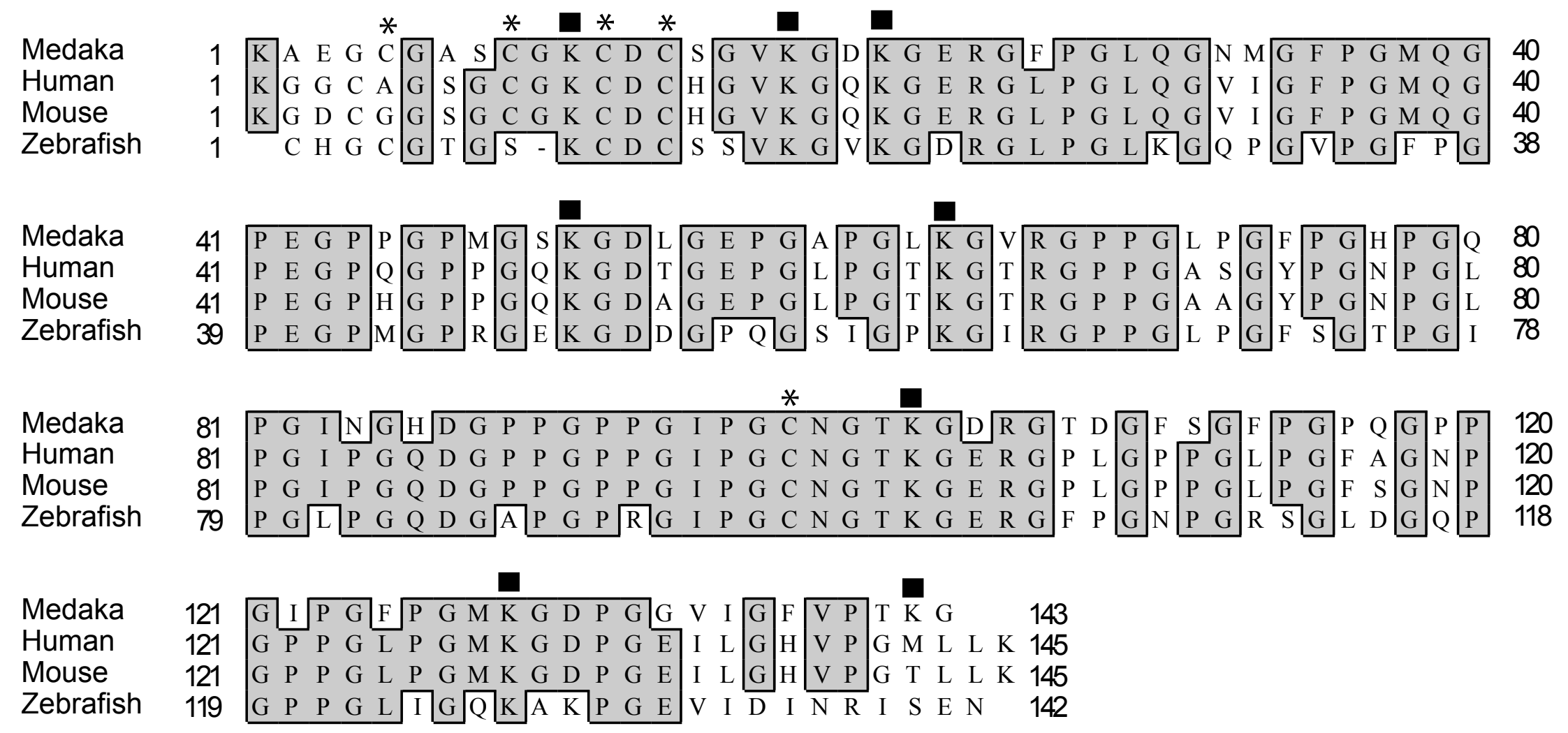

Fig. 2 Kato et al. 


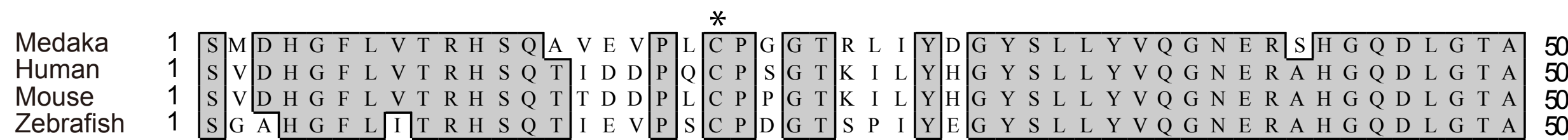
50 政 .
* * *

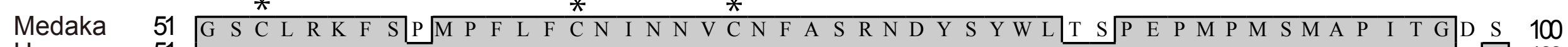

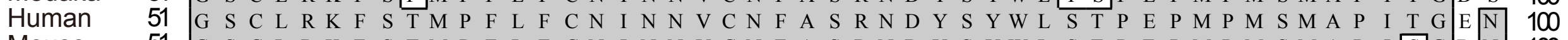

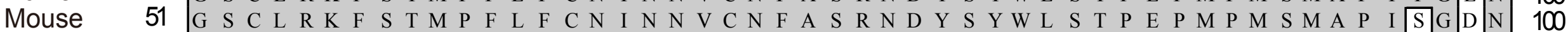

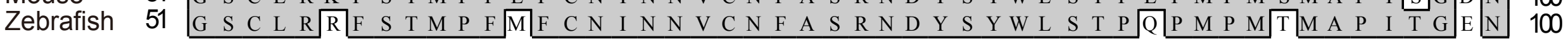

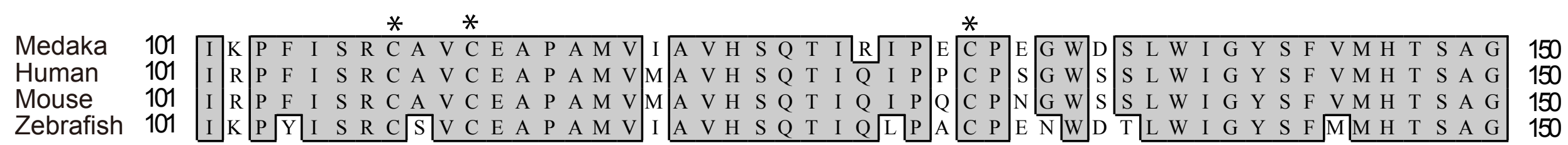

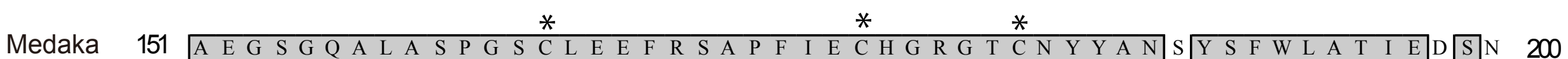

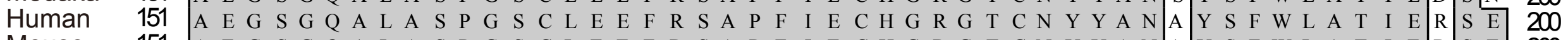

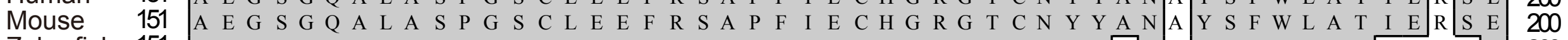

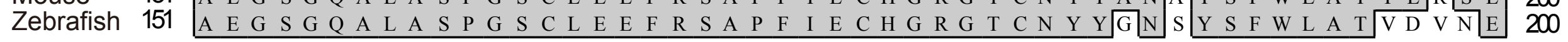

Medaka 201 M F 201 K K P

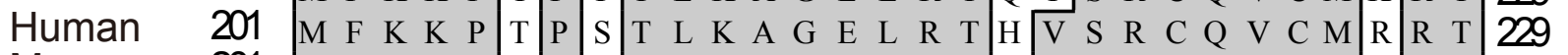

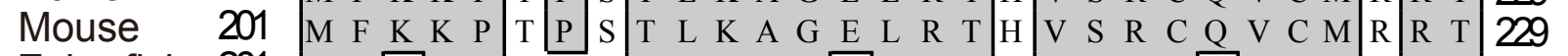
Zebrafish 201 M

Fig. 3 Kato et al. 

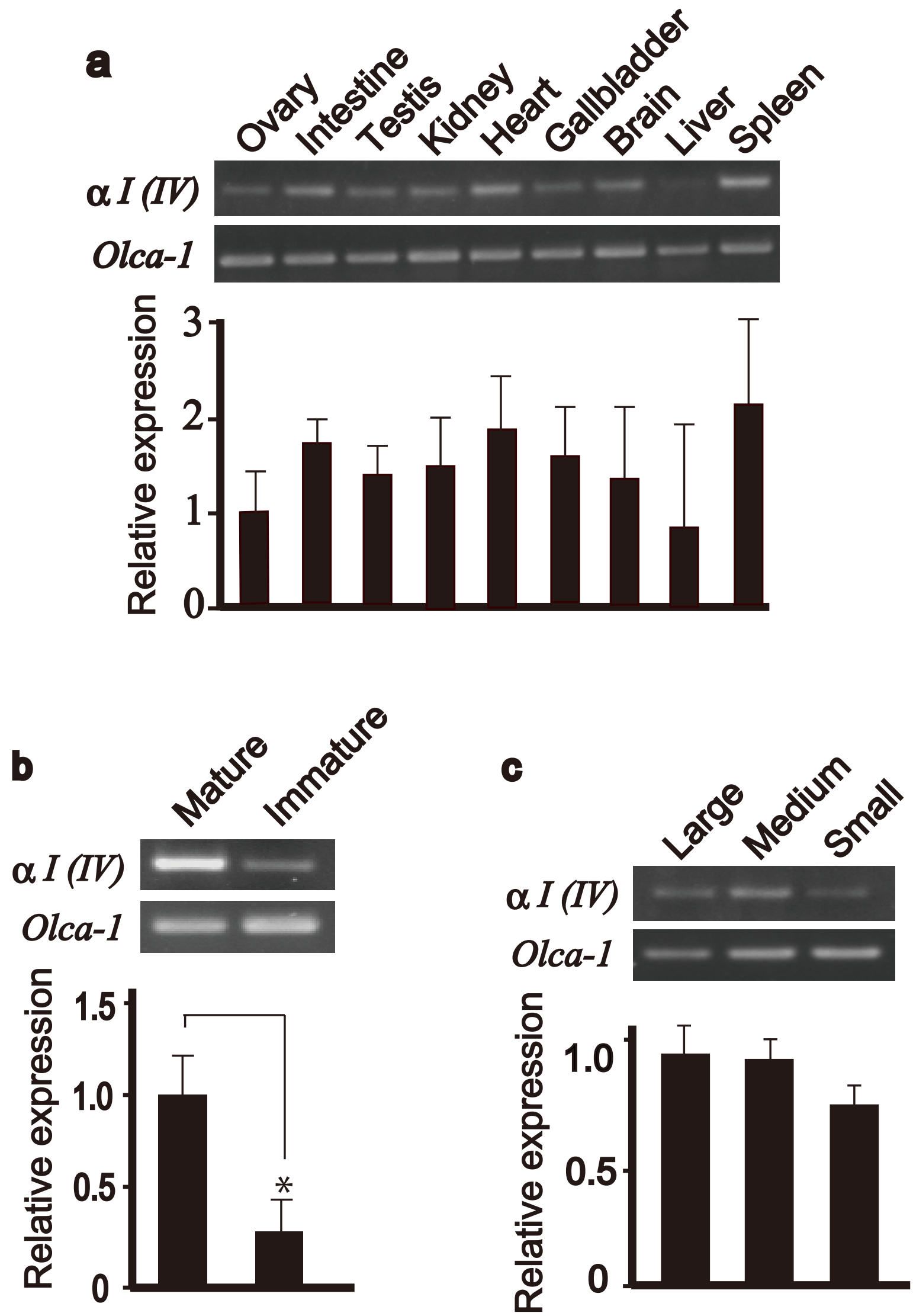

Fig. 4 Kato et al. 

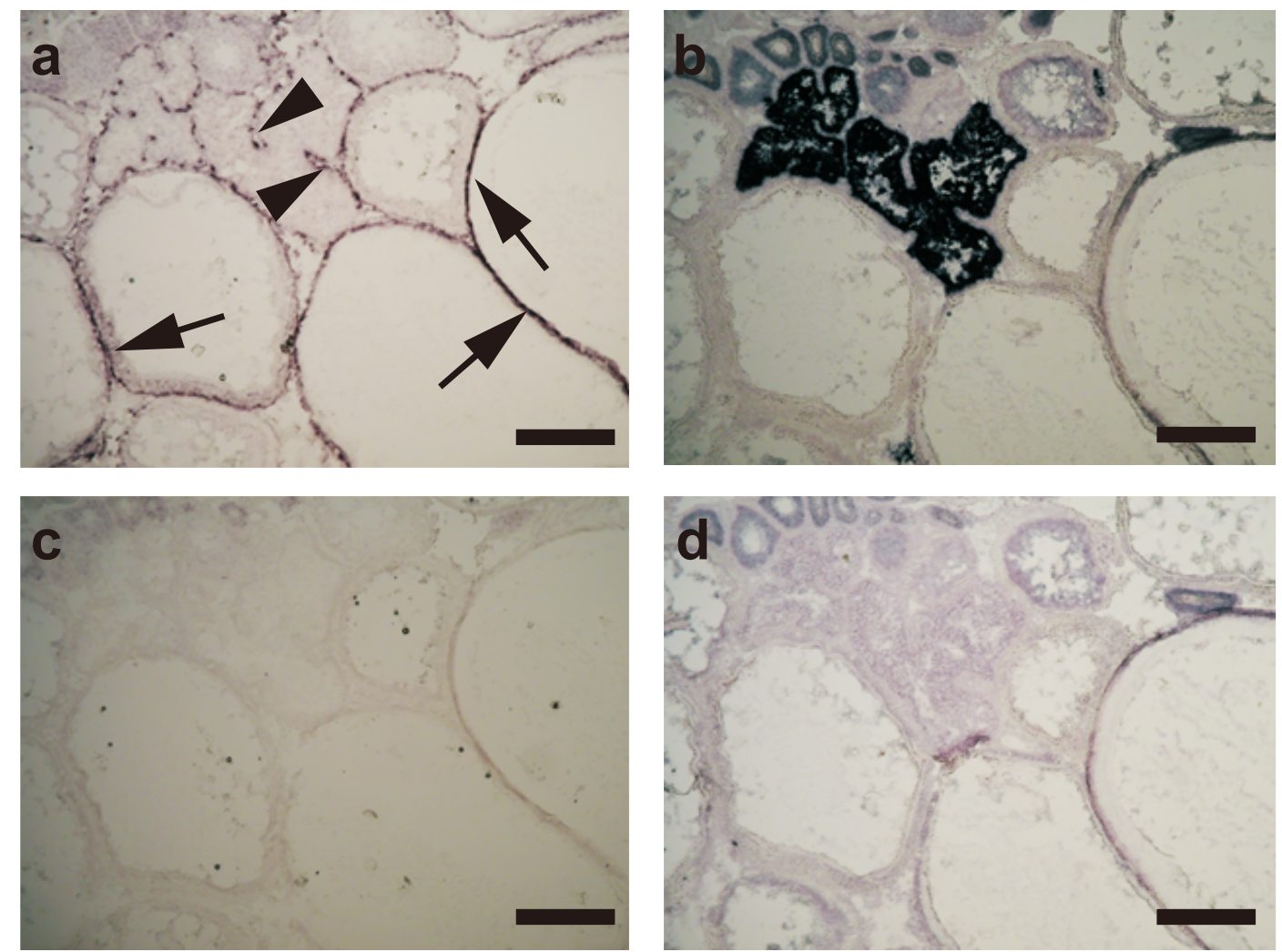

Fig. 5 Kato et al. 


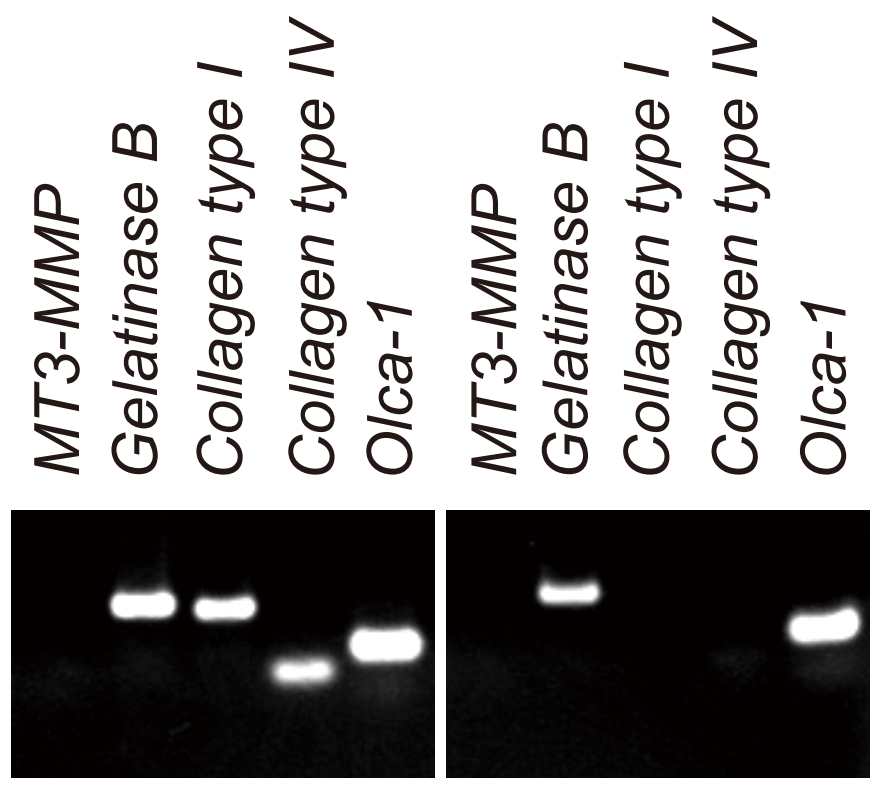

Follicle layer Granulosa cells

Fig. 6 Kato et al. 
a $\quad b$

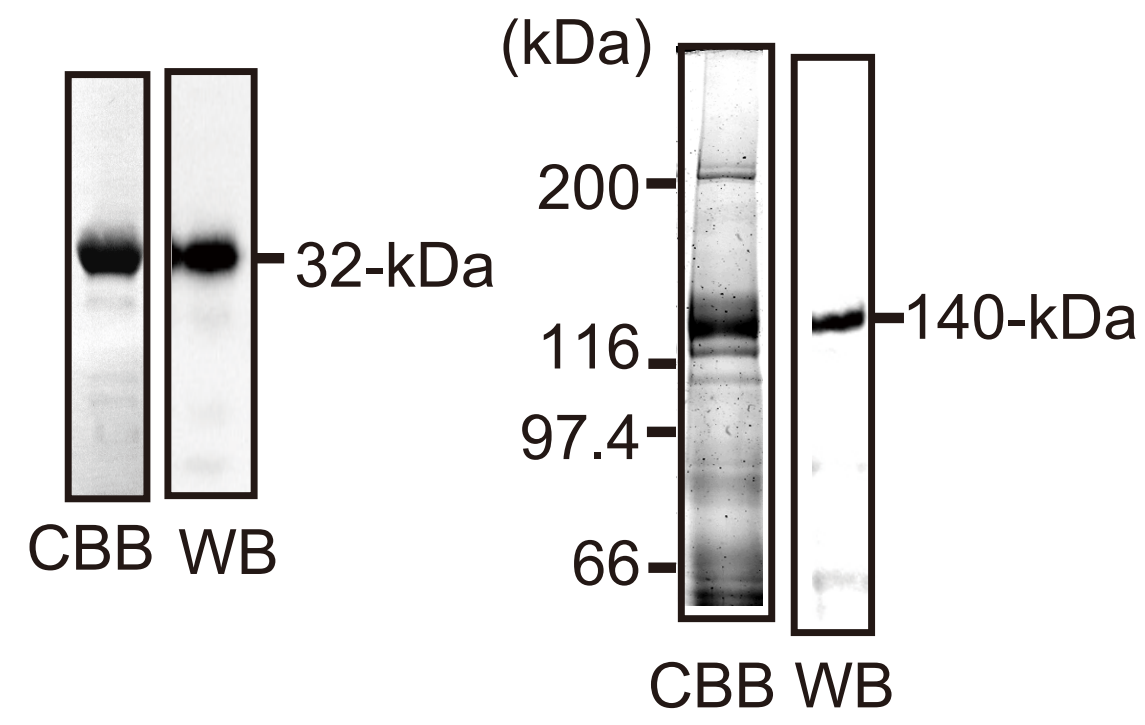

Fig. 7 Kato et al. 

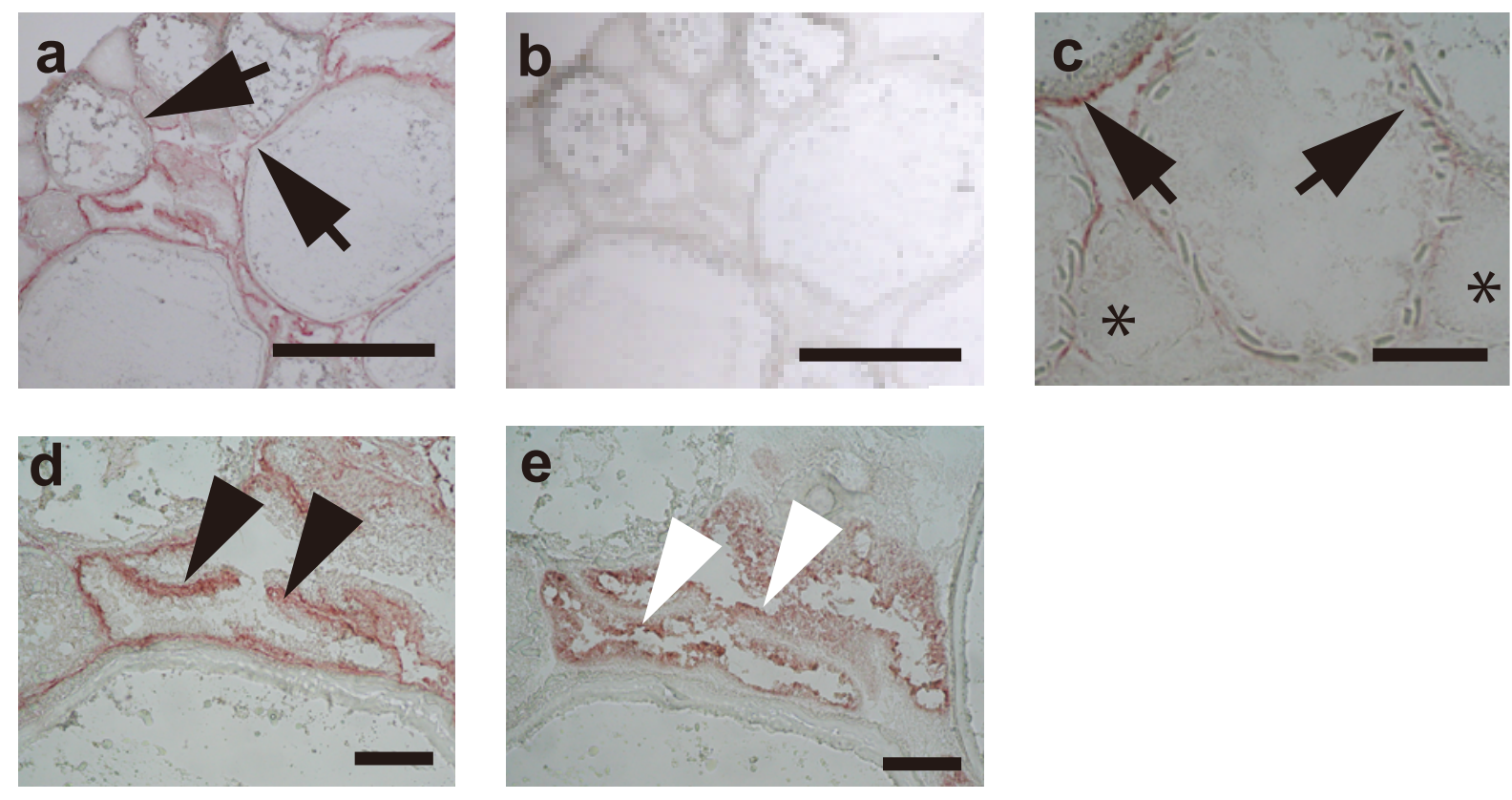

Fig. 8 Kato et al. 
Table 1 Primers used for RT-PCR

Primers were designed according to the sequence information from the database or reference: MT3-MMP (AB072929), gelatinase B (AB033755), collagen type I al-chain (AB280535), collagen type IV al-chain (AB525196), and Olca-1 (Kusakabe et al., 1999)

\begin{tabular}{|c|c|c|}
\hline Genes & Nucleotide sequences & Size of amplified products (bp) \\
\hline$\overline{M T 3-M M P}$ & $\begin{array}{l}\text { sense: 5'-AAGTCATGCAGTCTGCTATTGCTG-3' } \\
\text { antisense: 5'-TGGATCGTTGGAGTGTTCAAGAC-3' }\end{array}$ & 582 \\
\hline Gelatinase B & $\begin{array}{l}\text { sense: 5' - CAAAACAGATCCTAAACCAACTGT-3', } \\
\text { antisense: 5'-ATTTTAGGAGATCATATTTCACGT-3' }\end{array}$ & 710 \\
\hline Collagen type I a 1 chain & $\begin{array}{l}\text { sense: 5'-GAGAAATCTGGACTTGAA-3' } \\
\text { antisense: 5'-GTACAGAGCAACCGAGTT-3' }\end{array}$ & 536 \\
\hline Collagen type IV a 1 chain & $\begin{array}{l}\text { sense: 5'-ACCGGTGTTCTGGCTTTAC-3' } \\
\text { antisense: 5'-TTGGGGCGTGAAATCAGTG-3' }\end{array}$ & 209 \\
\hline Olca-1 & $\begin{array}{l}\text { sense: 5'-CAGACACGTATTTGCCTCTG-3' } \\
\text { antisense: 5'-CAAGTCGGAACACATGTGCA-3' }\end{array}$ & 312 \\
\hline
\end{tabular}


Table 2 Amino acid sequence identity (\%) between medaka collagen type IV $\alpha 1$-chain (this study, AB525196) and those of other species: humans (NP_001836), mice (NP_034061), Drosophila

(NP_723046), Zebrafish (NP_001116702), and Fugu (GSTENP00026005001). MacVector (Ver. 6.0,

Oxford Molecular) was used for the alignment analysis.

\begin{tabular}{lccc}
\hline Animal & 7S domain & Triple-helical domain & NC1 domain \\
\hline Humans & 64 & 55 & 86 \\
Mice & 66 & 56 & 86 \\
Drosophila & 57 & 52 & 56 \\
Zebrafish & 86 & 63 & 81 \\
Fugu & 34 & 44 & 82 \\
\hline
\end{tabular}

